Such disputes are unlikely to hinder science in the long run, but they can sow short-term confusion. Mars, which has been visited more than any other Solar System body in the past two decades, offers several examples. The latest concerns Curiosity, which touched down on 6 August.

The rover's chief target is a 5.5-kilometretall mountain in the middle of Gale crater' Early this year, the mission's science team asked the IAU to name the feature Mount Sharp, after Robert Sharp, a planetary geologist at the California Institute of Technology (Caltech) in Pasadena, who died in 2004. But that fell foul of the IAU rule book. Brad Smith, a retired astronomer and chairman of the IAU's Mars task group, points out that large features such as mountains must be named in Latin, after nearby light and dark features discerned on Mars by nineteenth-century astronomers. In May, the mountain was granted such a name: Aeolis Mons. (Craters can be named after people, however, so Sharp got a 152-kilometre crater just west of Gale.)

But the NASA team has been referring to the mound as Mount Sharp in public discussions and press releases. Curiosity project scientist John Grotzinger, a Caltech geologist, says he is "not trying to break the law" - rather, he wanted a userfriendly name simi-

"When an
organization
sets itself
up as the
holy mother
church,
you're always
going to get
heretics."
lar to that of Mars's Columbia Hills, which were named to commemorate the 2003 space-shuttle disaster soon after they were discovered by NASA's Spirit rover in 2004. Smith says that the hills are big enough to get an official name, but none was ever requested, so the informal name stuck.

In future, says Grotzinger, the Curiosity team will use Aeolis Mons on official maps, and will indicate in publications that Mount Sharp is an informal name.

That is fine with Smith, who points out that the Curiosity team can do whatever it wants in an unofficial capacity. "There's perhaps more drama being made about all this by the media than meets reality," he says. -

1. Thomas, P. C. et al. Icarus $\mathbf{1 2 8}$, 88-94 (1997).

2. Russell, C. T. et al. Science 336, 684-686 (2012).

3. Jaumann, R. et al. Science $\mathbf{3 3 6}, 687-690$ (2012).

4. Marchi, S. et al. Science 336, 690-694 (2012)

5. Schenk, P. et al. Science 336, 694-697 (2012).

6. De Sanctis, M. C. et al. Science 336,697-700 (2012)

7. Reddy, V. et al. Science 336, 700-704 (2012).

8. Archinal, B. A. et al. Celest. Mech. Dyn. Astr. 109, 101-135 (2011)

9. Hand, E. Nature 488, 262-263 (2012).

\title{
Companies set to fight food-label plan
}

\section{California's Proposition 37would add labels to all foods made from genetically modified crops.}

\section{BY MONYA BAKER}

A battle over genetically modified (GM) foods in California is turning into an expensive war. Agribusinesses and food manufacturers last week pledged US $\$ 13$ million to the campaign against a proposition that would require food to carry labels noting its GM content.

The money swells the opponents' coffers to \$25 million, promising months of campaigning before the public vote on the proposal in November. Supporters of Proposition 37, including organic farmers and environmentalists, have so far raised less than $\$ 2.5$ million.

Those in favour of labelling argue that the public has the right to know what is in their food, citing food-safety concerns and a general mistrust of corporate interests in agriculture. Opponents say that the labels will be perceived as warnings, stoking consumer hostility to genetic engineering. They also argue that the move would raise food costs, and expose grocers, farmers and food manufacturers to frivolous lawsuits for incorrect labelling.

Similar labelling proposals have failed in other states, but a victory in California could set a national precedent. "If the ballot initiative passes, it would mark a turning point for public activism in the United States," says Charles Benbrook, chief science consultant at the Organic Center, an organic farming advocacy group in Troy, Oregon.

Labelling would certainly have far-reaching consequences: around $94 \%$ of the soya beans and $88 \%$ of the maize (corn) grown in the United States is genetically engineered to resist herbicides, insect pests or both, according to the US Department of Agriculture. The plan could affect tens of thousands of brand-name products, and food manufacturers Coca-Cola, PepsiCo and Nestlé have each contributed more than \$1 million to the campaign; meanwhile, agribusinesses DuPont and Monsanto have chipped in more than $\$ 4$ million apiece.

The labels would not reflect how the crops have been modified, or the quantity of GM

\section{$\rightarrow$ NATURE.COM}

Can science feed the world?

go.nature.com/vt3rqo ingredients in a food. Meat from animals fed on GM crops would not need to be labelled.

Bob Goldberg, a plant geneticist at the University of California, Los Angeles, says the proposition is "anti-science", and could discourage research to develop drought-tolerant crops and more nutritious foods. Studies by the US National Academies ${ }^{1}$ and Britain's Royal Society of Medicine ${ }^{2}$ found no evidence that biotech crops are unsafe to eat. And, in June, the American Medical Association said that there was no scientific reason to label GM foods, but recommended that longterm studies should be vigilant for any health effects. Benbrook says that, far from being antiscience, the labelling could support health studies by helping to track people's food choices.

Pro-GM plant scientists also point out that the crops can benefit the environment by enabling farmers to use less-toxic herbicides and reduce insecticide use. But proponents of labels say that these benefits are temporary, and point to studies showing that weeds and insects have evolved resistance to the modified crops ${ }^{3}$. Seed companies can counter this by engineering new crops that are resistant to additional herbicides - such as a new soya bean developed by Dow AgroSciences of Indianapolis, Indiana - something that Benbrook argues will actually increase herbicide use.

In a poll earlier this month, $69 \%$ of Californians supported the proposition, and a national survey by Thomson Reuters in 2010 found that $93 \%$ of respondents wanted labels. But opinions can change: earlier this year, a cigarette tax that would have funded disease research was narrowly defeated at the ballot after $67 \%$ of voters initially supported it. That change of heart coincided with the cigarette lobby spending an estimated $\$ 50$ million on campaigning. Benbrook predicts that even more money will be thrown at the anti-GM-labelling campaign.

1. National Research Council Safety of Genetically Engineered Foods (National Academies Press, 2004) 2. Key, S. et al. J. R. Soc. Med. 101, 290-298 (2008).

3. Mortensen, D. A. et al. BioScience 62, 75-84 (2012).

\section{CORRECTION}

The News story 'Heatwaves blamed on global warming' (Nature 488, 143-144; 2012) should have said that the paper by Trenberth's team will appear in the Journal of Geophysical Research. 